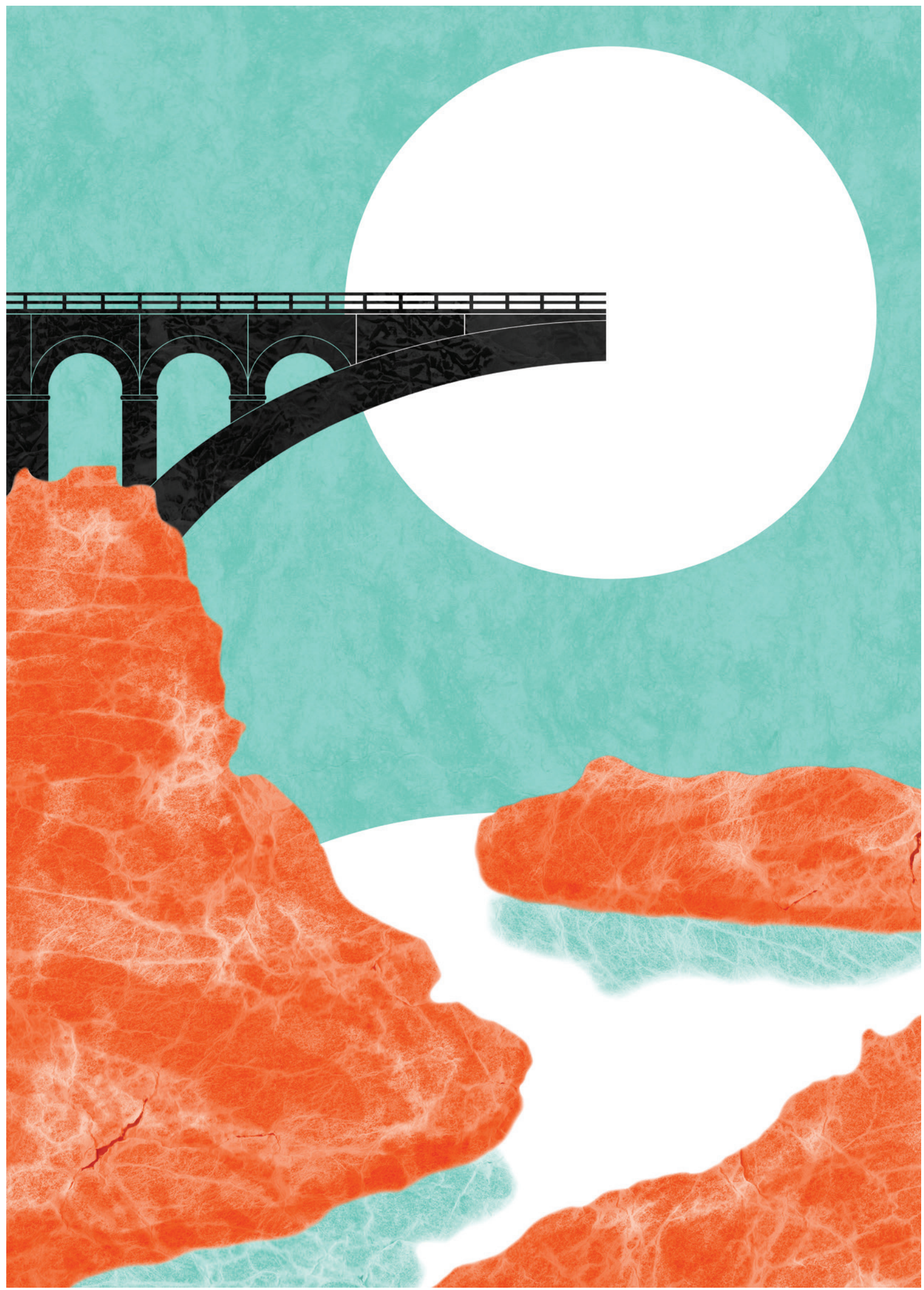

$\Delta$

'De BMGN en de kennisgeschiedenis'. (c) Frippery. 


\title{
De BMGN en de kennisgeschiedenis
}

\author{
KAREL DAVIDS
}

Kennisgeschiedenis is in de BMGN nu beter vertegenwoordigd dan dertig jaar geleden. Dat betekent niet dat de toenadering tussen kennisgeschiedenis en algemene geschiedenis in dit tijdschrift al volledig is geslaagd, en evenmin dat alle beschikbare kansen zijn benut. Kennisgeschiedenis is in de BMGN geen mainstream geworden, zo wordt in deze bijdrage betoogd, en de toenadering komt tot nu toe vooral van één kant. De mogelijkheden voor kennishistorisch onderzoek over nationale grenzen heen worden bovendien maar mondjesmaat verkend. De meeste artikelen blijven immers tot één helft van de Lage Landen beperkt. Aan de hand van verschillende voorbeelden wordt geïllustreerd welke interessante connecties en belangwekkende vergelijkingen tussen Noord en Zuid zouden kunnen worden onderzocht. De BMGN zou dus voor de kennisgeschiedenis meer kunnen betekenen dan zij in de afgelopen halve eeuw heeft gedaan.

History of knowledge is better represented at the BMGN nowadays than it was thirty years ago. This does not mean that a complete rapprochement between history of knowledge and general history has been accomplished in this journal, nor have all available opportunities been explored. History of knowledge has not become a mainstream school of thought in the BMGN, as is argued in this contribution, and to date the effort at rapprochement has been largely one-sided. Moreover, opportunities for research on history of knowledge beyond national borders are explored in very limited measure. After all, most articles continue to address only one half of the Low Countries. Various examples are presented here to illustrate which interesting connections and impressive comparisons could be examined between North and South. The BMGN could thus have done more to promote history of knowledge than it has in the past half century.

De BMGN en de kennisgeschiedenis zijn tegenwoordig meer met elkaar vertrouwd dan vroeger. Of beter gezegd: de BMGN en de kennisgeschiedenis minus de geschiedenis van de techniek. Over techniekgeschiedenis is in de eerste halve eeuw van het bestaan van dit tijdschrift eigenlijk nooit iets te 
vinden, behalve af en toe in een boekbespreking of discussiedossier. Voor de rest van wat nu 'kennisgeschiedenis' wordt genoemd ligt dat gelukkig anders. ${ }^{1}$ Tussen 1970 en 2000 kreeg dit domein van de geschiedenis in de BMGN bijna geen aandacht, afgezien van een enkel stuk over Erasmus of Darwin, maar sinds de eeuwwisseling gaat er haast geen jaar voorbij of er staat wel een artikel in over medische geschiedenis of over een bepaalde tak van wetenschapsgeschiedenis. Kennisgeschiedenis heeft in het tijdschrift langzamerhand een min of meer vaste plaats veroverd (zie grafiek 1). Erasmus en Darwin maken nog geregeld hun opwachting, maar ze zijn niet langer eenzame figuren; ze zijn nu een onderdeel van een hele zwerm aan kennishistorische casestudies. Hier doet zich hetzelfde fenomeen voor dat Pieter Huistra en Bram Mellink in dit nummer voor de BMGN als geheel constateren: het tijdschrift loopt zelden voorop, maar gaat wel met de tijd mee. $^{2}$

De bijdragen over kennisgeschiedenis in de BMGN vertonen een zekere spreiding over de vroegmoderne en moderne tijd, maar het zwaartepunt ligt toch wel op de negentiende en twintigste eeuw. Daarin wijkt de geschiedschrijving over de ontwikkeling van kennis niet af van de historiografie in het algemeen (zie grafiek 2). ${ }^{3}$ Ook inhoudelijk is in het tijdschrift een toenadering van kennisgeschiedenis tot de algemene geschiedenis te zien. Zo leverden specialisten in de geschiedenis van de geneeskunde en de pedagogiek in een themanummer uit 2007 een bijdrage aan de canondiscussie door te analyseren hoe in Nederland en Vlaanderen in de loop der eeuwen over de vorming van de 'volmaakte mens' werd gedacht. ${ }^{4}$ In het voorwoord van een themanummer uit 2017 dat aan de medische geschiedenis in de twintigste eeuw was gewijd, benadrukten de gastredacteuren dat de artikelen illustreerden hoezeer de ontwikkeling van de gezondheidszorg was verweven met sociale en ideologische conflicten. Medische geschiedenis was duidelijk niet alleen relevant voor een kleine groep van specialisten, luidde de boodschap; het vakgebied kon ook een waardevolle inbreng leveren in bredere historische debatten, zoals over de groei van de

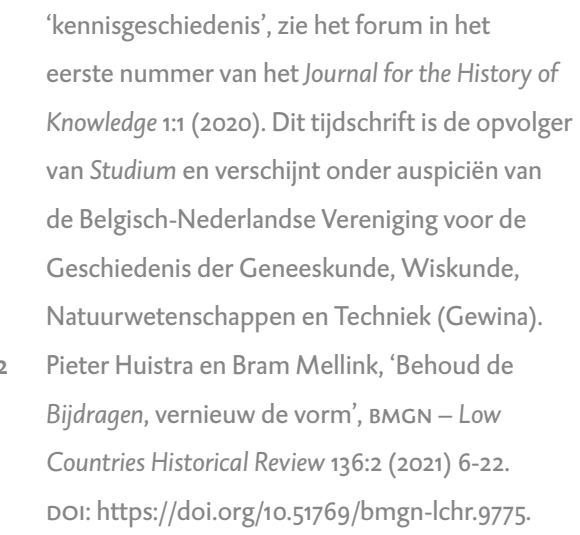

3 Zie ook Marc Boone en Tom Verschaffel, "'Et pour les Belges la même chose"? Het Vlaamse aandeel in de BMGN', BMGN - Low Countries Historical Review 136:2 (2021) 24-41. DOI: https:// doi.org/10.51769/bmgn-lchr.9781.

4 Catrien Santing, 'De menselijke canon en de Lage Landen. Voorbije pogingen de Nederlanders en Vlamingen te modelleren', Bijdragen en Mededelingen betreffende de Geschiedenis der Nederlanden/The Low Countries Historical Review 122:4 (2007) 481-483. DOI: https://doi.org/10.18352/ bmgn-Ichr.6663. 
verzorgingsstaat of de betwiste functies van bepaalde instituties. 'Medical history', zo claimden de gastredacteuren, 'is strongly embedded in social, cultural and political history'. ${ }^{5}$ Amen to that - en wat mij betreft zou dat ook mogen gelden voor 'global history' en 'economic history'.

Betekent dat nu dat kennisgeschiedenis intussen mainstream is geworden? Is het potentieel van de kennisgeschiedenis in de BMGN hiermee al volledig gerealiseerd? En omgekeerd: kan het tijdschrift voor de kennisgeschiedenis meer betekenen dan het tot nu toe heeft gedaan? Het antwoord op de eerste twee vragen is nee, op de laatste ja. Hieronder zal ik uitleggen waarom.

Tijdschrift voor de Geschiedenis der Geneeskunde, Wiskunde, Natuurwetenschappen en Techniek - zo heette oorspronkelijk het vaktijdschrift van kennishistorici uit de Lage Landen, dat in 1978 begon te verschijnen. De oprichting van dit tijdschrift vond niet toevallig plaats kort na het verdwijnen van het Belgische tijdschrift Scientiarum Historia: Tijdschrift voor de Geschiedenis van de Wetenschappen en de Geneeskunde, dat in de jaren zestig en zeventig voor zowel Nederlandse als Vlaamse wetenschapshistorici een belangrijk platform was geweest. ${ }^{6}$ Veel van de artikelen in het nieuwe tijdschrift hadden betrekking op het specialisme dat in de lange naam voorop stond. Dat was niet zo verwonderlijk, omdat het 'groene tijdschrift' (zoals het in de wandeling begon te heten) vooral als publicatiekanaal diende voor leden van het gelijknamige genootschap en de overgrote meerderheid van de genootschapsleden lange tijd bestond uit 'liefhebbers' die met name uit de geneeskundige hoek kwamen. De verhouding tussen 'professionele' wetenschapshistorici, verbonden aan universiteiten, en de talrijke artsen, apothekers en andere mensen met een medische achtergrond die in hun vrije tijd graag iets aan de geschiedenis van hun eigen vak deden, was overigens zelden zonder spanningen. ${ }^{7} \mathrm{De}$ geschiedenis van de natuurwetenschappen kwam in het 'groene tijdschrift' wat minder aan bod en die van de wiskunde of techniek bijna niet. Techniekhistorici vonden na 1984 onderdak in het Jaarboek voor de Geschiedenis van Bedrijf en Techniek en later in het NEHA-Jaarboek voor Economische, Bedrijfs-en Techniekgeschiedenis.

5 Frank Huisman, Joris Vandendriessche en Kaat Wils, 'Blurring Boundaries: Towards a Medical History of the Twentieth Century', BMGN - Low Countries Historical Review 132:1 (2017) 3-15, 5. DOI: https://doi.org/10.18352/bmgn-lchr.10306.

6 Geert Vanpaemel, 'Tussen lokaal belang en wetenschappelijke ambitie: de publicatiegeschiedenis van Scientiarum Historia (1959-2006)', Studium 12:4 (2019) 174-184, 180. DOI: http://doi.org/10.18352/studium.1554.

7 Rienk Vermij, 'Tussen liefhebbers en professionals. Het "groene tijdschrift", 1978-2007', Studium 12:4 (2019) 218-225. DOI: http://doi.org/10.18352/studium.10207. 
Ook de bijdragen over kennisgeschiedenis die in de afgelopen twintig jaar in de BMGN zijn verschenen, waren vaak aan thema's uit de medische geschiedenis of de geschiedenis van de levenswetenschappen gewijd, zoals gezondheidszorg, hygiënisme, ziekte, waanzin, psychiatrie, ontleedkunde of fysische antropologie. Anders dan in het 'groene tijdschrift' zijn de auteurs in de BMGN niet meer 'liefhebbers' met een medische achtergrond, maar 'professionals' die een opleiding als historicus hebben gevolgd en daarbinnen zich hebben toegelegd op de kennisgeschiedenis. Voor deze groep is de BMGN een interessant forum omdat ze daar een verbinding kunnen maken tussen hun eigen specialisme en debatten over de geschiedenis van racisme, kolonialisme, discriminatie en uitsluiting, die in het historisch onderzoek in Nederland en België steeds meer centraal zijn komen te staan. In de komende jaren zal dat vast en zeker ook gaan gelden voor een thema als de relatie tussen epidemieën en globalisering. Zo'n verbinding is zonder meer winst voor zowel de kennisgeschiedenis als de algemene geschiedenis.

Maar daarmee blijft nog een flink deel van de kennisgeschiedenis buiten beeld. Wat kan de geschiedenis van de natuurwetenschappen, wiskunde of techniek bijdragen aan bredere historische discussies? Die invalshoek vinden we in de BMGN tot nu toe nauwelijks terug. Voor de geschiedschrijving van de humaniora of de sociale wetenschappen, die ook tot de 'kennisgeschiedenis' behoren, is de situatie niet veel anders. Daarom is het te vroeg om nu al te zeggen dat kennisgeschiedenis mainstream is geworden.

Een andere reden waarom zo'n conclusie prematuur is, ligt in een zeker gebrek aan wederkerigheid. De drang van kennishistorici om aansluiting te zoeken bij andere groepen historici lijkt groter te zijn dan omgekeerd. Er worden wel bruggen gebouwd maar vooral van één kant. Aan de overkant is de animo kleiner. Cultuurhistorici verdiepen zich vaak wel in ontwikkelingen in de wetenschapsgeschiedenis, medische geschiedenis of andere terreinen van de kennisgeschiedenis, maar dat gaat minder op voor politiek historici, sociaal historici of economisch historici. Toch is ook voor hen winst te behalen als ze zich meer op de hoogte zouden stellen van wat er in de kennisgeschiedenis gebeurt. Een goed voorbeeld is een bijdrage van Ronald Kroeze en Sjoerd Keulen aan een forum over de 'manager in de politiek' in de BMGN van 2012. ${ }^{8}$ Daarin betogen ze dat de politieke geschiedenis er baat bij kan hebben om begrippen, inzichten en methoden te ontlenen aan historische managementstudies - ook weer een onderdeel van wat nu 'kennisgeschiedenis' heet. In de managementwetenschappen is er intussen namelijk veel onderzoek gedaan omtrent historische veranderingen in de taal, cultuur en praktijk van management. Politiek historici kunnen daar gebruik van maken om de opmars van de managerslogica in de 
politiek in de jaren tachtig en negentig van de twintigste eeuw te begrijpen. Kennisgeschiedenis kan helpen om te snappen what made Lubbers en Kok tick.

\section{Parallelle wegen, nieuwe uitzichten}

Kennishistorici die in de BMGN publiceren zijn zowel uit België als Nederland afkomstig. Het aandeel van auteurs uit elk van beide landen ontloopt elkaar niet veel. Dat is minder vanzelfsprekend dan het lijkt. Onder alle auteurs die de laatste vijftig jaar in de BMGN publiceerden, nam het aantal Belgen pas vanaf 2005 duidelijk toe. ${ }^{9}$ In het Tijdschrift voor de Geschiedenis der Geneeskunde, Wiskunde, Natuurwetenschappen en Techniek verscheen in de eerste twaalf jaargangen nota bene maar één artikel van een Vlaamse auteur. Ook na 1990 bleven Belgische bijdragen in het 'groene tijdschrift' schaars. Omgekeerd publiceerden Nederlandse auteurs zelden in het in 1990 heropgerichte Scientiarum Historia. ${ }^{10}$ De situatie was weinig anders in het tijdschrift Studium, dat in 2008 ontstond uit een fusie van het 'groene tijdschrift', Scientiarum Historia, en de Nederlands-Belgische Nieuwsbrief Universiteitsgeschiedenis. Van de auteurs van de 219 bijdragen die tot 2019 in Studium verschenen, kwam $76 \%$ uit Nederland, $16 \%$ uit België en $8 \%$ uit een ander land. ${ }^{11}$ Die verhouding weerspiegelt in zekere zin de zwakkere institutionele positie van de wetenschapsgeschiedenis en medische geschiedenis aan Belgische universiteiten. Kennisgeschiedenis is daar minder in het onderwijs en onderzoek verankerd dan in Nederland. Terwijl in Nederland het aantal masterstudenten en promovendi dat zich op dit terrein specialiseerde na de eeuwwisseling duidelijk toenam, is dat in België maar in beperkte mate het geval geweest. De omvang van de groep 'professionals' groeide in het Noorden harder dan in het Zuiden. ${ }^{12}$ Wat kennishistorici in Nederland en België gemeen hadden, was hun toenemende internationale oriëntering. Ze gingen meer publiceren in het Engels en manifesteerden zich meer in internationale tijdschriften en op internationale conferenties. Daarin verschilden ze overigens niet van historici in andere disciplines.

Ook al is de kennisgeschiedenis over beide landen in de BMGN de laatste tijd aardig vertegenwoordigd, de mogelijkheden voor kennishistorisch onderzoek over de landsgrenzen heen zijn nog lang niet uitgeput. Het potentieel van de Nederlands-Belgische kennisgeschiedenis is groter dan

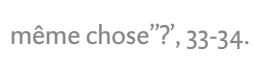

11 Geert Somsen en Ilja Nieuwland, 'A New Beginning comes to an end: Studium, 2008-2019', 
tot nu toe in dit tijdschrift tot uiting komt. En de BMGN zou meer kunnen betekenen voor de kennisgeschiedenis dan ze in de afgelopen jaren heeft gedaan, hoezeer de redactie zich al heeft ingespannen om artikelen hierover voor het tijdschrift aan te trekken.

Publicaties over kennisgeschiedenis van Belgische en Nederlandse auteurs in de BMGN vertonen namelijk een patroon dat ook in andere (sub) disciplines van de geschiedschrijving niet onbekend is: er worden slechts sporadisch vergelijkingen met het buurland gemaakt of connecties tussen beide landen onderzocht, zelfs als artikelen over soortgelijke onderwerpen gaan. De wegen lopen parallel, maar kruisen elkaar zelden. Het tekort aan grensoverschrijdende bijdragen wordt in dit nummer ook door Marc Boone en Tom Verschaffel geconstateerd. Huistra en Mellink spreken over 'het Belgisch-Nederlandse kader waaraan de BMGN nu eenmaal vastzat' - wat niet op een groot enthousiasme voor de mogelijkheden van dit perspectief voor het historisch onderzoek duidt. ${ }^{13}$

Eén van de weinige uitzonderingen wat de kennisgeschiedenis betreft, is een bijdrage van Angelo De Bruycker en Djoeke van Netten in 2008. ${ }^{14}$ De auteurs onderzochten daarin of de traditionele visie dat de bloei van de natuurwetenschap in de Republiek in de zeventiende eeuw voortkwam of zelfs ten koste ging van de bloei in de Zuidelijke Nederlanden, houdbaar is. Om het antwoord te vinden deden ze precies dat wat in andere artikelen bijna nooit gebeurt. Ze maakten rechtstreekse vergelijkingen tussen de wetenschapsbeoefening in het Zuiden en het Noorden en probeerden in te schatten wat het effect was van een specifieke connectie tussen beide delen van de Nederlanden, namelijk de stroom van kennismigranten van Zuid naar Noord tussen circa 1580 en 1630 , waarvan de Nederlandse wiskundige Simon Stevin een perfect voorbeeld is. De auteurs vroegen zich af of dit echt een zero-sum game was. Betekende emigratie naar het Noorden automatisch een verlies voor het Zuiden? Het was, denk ik, geen toeval dat deze bijdrage werd geschreven in het kader van een project gefinancierd door het Vlaams-Nederlands Comité van Fwo/Nwo, dat speciaal beoogde zulk grensoverschrijdend onderzoek te stimuleren. Het is jammer dat dit vruchtbare financieringsinstrument is verdwenen.

Zo'n comparatieve benadering zou op veel meer onderwerpen en perioden uit de Belgische en Nederlandse kennisgeschiedenis kunnen worden toegepast. Kennismigratie binnen de Nederlanden was immers niet beperkt même chose”?'; Huistra en Mellink, 'Behoud de Bijdragen, vernieuw de vorm'.
Republiek en de Spaanse Nederlanden', Bijdragen en Mededelingen betreffende de Geschiedenis der Nederlanden/The Low Countries Historical Review 123:1 (2008) 3-30. DOI: https://doi.org/10.18352/ bmgn-Ichr.6732. 
tot de tijd van Stevin cum suis, of die van Erasmus. Het fenomeen zou ook onderzocht kunnen worden voor bijvoorbeeld de periode van de hereniging en scheiding van Noord en Zuid na 1815. De bekendste kennismigrant uit die tijd is waarschijnlijk Jan Rudolf Thorbecke, maar er zijn er nog veel meer heen en weer gegaan, al dan niet vrijwillig. Zo weten we dat Jean-Baptiste Vifquain uit Doornik als hoofdingenieur bij Waterstaat een hangbrug over de Lek bij Vianen heeft ontworpen en in een adviescommissie voor de verbetering van de grote rivieren heeft gezeten, dat Frans Jan Stamkart uit Amsterdam vanaf 1826 rijksleraar in de zeevaartkunde in Antwerpen is geweest (tot hij vier jaar later 'als Hollander' moest vluchten), en dat sommige Belgische katoenfabrikanten na de Opstand, aangemoedigd door financiële prikkels van de Nederlandsche Handel-Maatschappij, hun zaken naar Overijssel en Haarlem hebben verplaatst. ${ }^{15}$ Maar de totale omvang, aard en impact van de kennismigratie tussen Noord en Zuid vanaf de Napoleontische Tijd tot het midden van de negentiende eeuw is nog nauwelijks in kaart gebracht. Dat geldt evengoed voor een latere periode van toenadering tussen Nederland en België, die we nu nog zelf meemaken: de tijd van de vorming van de Benelux en de Europese eenwording.

Ook wat betreft de ontwikkeling van kennisinfrastructuur is het zinvol om vergelijkingen te maken en connecties te onderzoeken tussen Noord en Zuid. Een paar voorbeelden: waarom werden in de begintijd van het Verenigd Koninkrijk der Nederlanden drie universiteiten in het Zuiden opgericht en niet twee of één? Een belangrijk argument waarmee de regering haar besluit verdedigde, zo achterhaalde Pieter Dhondt, was de noodzaak om voor een evenwicht te zorgen tussen beide delen van het rijk. In het Noorden hadden Leiden, Groningen en Utrecht hun universiteit behouden. Daarom voelde koning Willem I zich verplicht om ook drie steden in het Zuiden, namelijk Leuven, Luik en Gent, een universiteit te gunnen. ${ }^{16}$ Dat streven naar evenwicht kwam niet alleen in het hoger onderwijs tot uiting. Bij de vestiging van lectoraten in de zeevaartkunde gebeurde hetzelfde in omgekeerde richting. Toen in 1823 van staatswege twee leraren in havensteden in het

initiatief', Tijdschrift voor Zeegeschiedenis 4 (1985) 164-190, 169; Richard T. Griffiths, Industrial Retardation in the Netherlands 1830-1850 (Den Haag 1979) 142. DOI: https://doi.org/10.1007/97894-017-1877-6.

16 Dhondt, 'De verloren strijd voor één universiteit in België, 1814-1835', Bijdragen en Mededelingen betreffende de Geschiedenis der Nederlanden/The Low Countries Historical Review 121:2 (2006) 197-221, 207. DOI: https://doi. org/10.18352/bmgn-Ichr.6394. 
Zuiden (Antwerpen en Oostende) werden aangesteld, werden tegelijkertijd twee soortgelijke posities in havensteden in het Noorden gecreëerd (Amsterdam en Rotterdam), ook al bestond daar eigenlijk niet veel behoefte aan. ${ }^{17}$ De oprichting van het eerste door de staat gesubsidieerde onderzoeksinstituut in Nederland in 1854, het Koninklijk Nederlands Meteorologisch Instituut, is evenmin goed te begrijpen zonder de Belgische context erbij te betrekken. De Utrechtse hoogleraar Christophorus Buys Ballot kwam op het idee om in Nederland een meteorologisch observatorium te stichten nadat hij in 1847 het Observatoire Royal in Brussel had bezocht, waar directeur Adolphe Quetelet al jarenlang zowel het weer als de sterrenhemel observeerde. ${ }^{18}$ Over zulke connecties tussen de institutionele ontwikkelingen in Noord en Zuid valt nog veel meer systematisch onderzoek te doen.

Hetzelfde geldt voor ontwikkelingen op inhoudelijk vlak, zoals het ontstaan van nieuwe wetenschappelijke disciplines. Eén van de kenmerken van disciplinevorming is de oprichting van een tijdschrift dat het eigen vakgebied op de kaart kan zetten en de onderlinge communicatie van de beoefenaars makkelijker kan maken. Om dat proces te begrijpen kan het weer nuttig zijn om over de Belgisch-Nederlandse grens heen te kijken. Wat in het Zuiden gebeurde, kon effect hebben in het Noorden, en omgekeerd. Vakgenoten in het ene land konden proberen het voorbeeld van hun collega's in het andere land na te volgen, of zich juist van hun invloed los te maken. Een voorbeeld van zo'n transnationaal emancipatieproces is de ontwikkeling in de volkskunde, waar Piet de Rooy in de BMGN van 2003 een reviewartikel aan wijdde. Het Volkskundig Bulletin werd in 1975 opgericht in Nederland, nadat een breuk was ontstaan in de redactie van het Vlaams-Nederlandse tijdschrift Volkskunde, dat sinds 1940 het toonaangevende blad op het vakgebied was geweest. Verschil van inzicht tussen Nederlandse en Vlaamse redactieleden over hoe het verder moest met de volkskunde lag daaraan ten grondslag. ${ }^{19}$ Een voorbeeld van het andere effect levert de wetenschapsgeschiedenis zelf: na de verdwijning van Scientiarum Historia in 1974 volgden de Nederlanders het Belgische model na door een eigen tijdschrift te beginnen (Tijdschrift voor de Geschiedenis der Geneeskunde, Wiskunde, Natuurwetenschappen en Techniek).

Het Belgisch-Nederlands kader van de BMGN hoeft, kortom, geen keurslijf te zijn maar kan integendeel als springplank dienen. En wie de sprong waagt, krijgt nieuwe uitzichten.

academics came to dominate the science of the weather, 1830-1870 (proefschrift; Vrije Universiteit Amsterdam 2017) 41.

Davids, 'Het zeevaartkundig onderwijs', 167-169.

Azadeh Achbari, Rulers of the Winds. How studies over de geschiedenis van de volkskunde in Nederland', Bijdragen en Mededelingen betreffende de Geschiedenis der Nederlanden 118:2 (2003) 193-205. DOI: https://doi.org/10.18352/bmgnIchr.5834; Jan Theeuwissen, 'Mijmerend en bewonderend stilstaan', Volkskundig Bulletin 26:1 (2000) 69-72. 


\section{Tot besluit}

De BMGN is in de kennisgeschiedenis meer een volger dan een trendsetter geweest. Dat laatste valt bij een algemeen historisch tijdschrift uiteraard ook niet direct te verwachten. Het is op zich al respectabel dat de BMGN zich heeft opengesteld voor enkele nieuwe ontwikkelingen in dit specifieke vakgebied. Maar er is meer te doen. Kennisgeschiedenis zou meer 'opgepikt' kunnen worden in publicaties van andere historici. Hele bruggen zijn beter dan halve. En de dubbele nationaliteit van het tijdschrift zou in casestudies over kennisgeschiedenis meer uitgebaat kunnen worden. Vergelijkingen over grenzen heen hoeven natuurlijk niet per se tussen België en Nederland gemaakt te worden, en er zijn allicht veel meer relevante transnationale connecties te onderzoeken dan alleen die tussen deze twee landen, maar dwarsverbanden in de Lage Landen verdienen in de kennisgeschiedenis wel meer aandacht dan ze nu meestal in het tijdschrift krijgen. Daar kan juist de BMGN voor een meerwaarde zorgen. Kennishistorici zullen er over vijftig jaar met gepaste waardering over schrijven.

Karel Davids is emeritus hoogleraar Economische en Sociale Geschiedenis aan de Vrije Universiteit Amsterdam. Hij interesseert zich voor wereldgeschiedenis, maritieme geschiedenis, kennisgeschiedenis en de verhouding tussen mensen en dieren. Hij publiceerde onder meer Global Ocean of Knowledge, 1660-1860. Globalization and Maritime Knowledge in the Atlantic World (Londen 2020) en De Eckhardts. Een uitvindersfamilie in Nederland en Engeland 1670-1830 (Amsterdam 2021). Samen met Fokko Jan Dijksterhuis, Ida Stamhuis en Rienk Vermij redigeerde hij Rethinking Stevin, Stevin Rethinking. Constructions of a Dutch Polymath (Leiden 2021). E-mail: c.a.davids@ vu.nl. 